\title{
龙泉镁质闪石的拓扑交生 ${ }^{*}$
}

\author{
薛纪越马军 \\ （南京大学地球科学系,南京 210008) \\ 张富 生 \\ (南京大学现代分析中心, 南京 210008)
}

关业词拓扑交生、镁闪石、直闪石

\section{一、龙泉镁质闪石的产出地质环境及一般特征}

本文研究的镁质闪石呈束状或纤维状集合体,分布在龙泉构造混杂岩带的檄榄岩块周围. 晶体长度从数裏米至 1 厘米左右. 偏光显微镜下斜消光, $\mathrm{C} \wedge \mathrm{Ng}-10^{\circ}-13^{\circ}$; 并见橄梅石、

表 1 龙泉镁质闪石的电子探针分析结果

\begin{tabular}{|c|c|c|c|}
\hline 分析点号 & 1 & 2 & 3 \\
\hline $\mathrm{SiO}_{2}$ & 57.88 & 57.57 & 57.48 \\
\hline $\mathrm{FeO}^{*}$ & 12.34 & 11.25 & 11.27 \\
\hline $\mathrm{MgO}$ & 26.38 & 26.38 & 26.52 \\
\hline $\mathrm{Al}_{2} \mathrm{O}$ & 0.14 & 0.18 & 0.17 \\
\hline $\mathrm{TiO}_{2}$ & 0.07 & 0.01 & 0.00 \\
\hline $\mathrm{Cr}_{2} \mathrm{O}_{3}$ & 0.04 & 0.14 & 0.10 \\
\hline $\mathrm{MnO}_{2}$ & 0.55 & 0.49 & 0.47 \\
\hline $\mathrm{Na}_{2} \mathrm{O}$ & 0.03 & 0.06 & 0.05 \\
\hline $\mathrm{K}_{2} \mathrm{O}$ & $0.0 f$ & 0.00 & 0.00 \\
\hline $\mathrm{CaO}_{\mathrm{a}}$ & 0.89 & 0.55 & 0.53 \\
\hline 总和 & 98.32 & 96.63 & 96.59 \\
\hline \multicolumn{4}{|c|}{ 以 23 个篻为䔄础计算的阳离子数 } \\
\hline $\mathrm{si}$ & 7.96 & 8.00 & 8.00 \\
\hline $\mathrm{Fe}$ & 1.42 & 1.30 & 1.31 \\
\hline $\mathrm{Mg}$ & 5.40 & 5.46 & 5.50 \\
\hline $\mathbf{A l}$ & 0.02 & 0.02 & 0.02 \\
\hline $\mathbf{T i}$ & 0.01 & 0.00 & 0.00 \\
\hline$C_{r}$ & 0.00 & 0.02 & 0.01 \\
\hline$M n$ & 0.06 & 0.06 & 0.06 \\
\hline $\mathrm{Na}$ & 0.01 & 0.02 & 0.01 \\
\hline $\mathrm{K}$ & 0.00 & 0.00 & 0.00 \\
\hline $\mathrm{Ca}_{\mathrm{a}}$ & 0.13 & 0.08 & 0.08 \\
\hline $\mathrm{Mg} / \mathrm{Fe}+\mathrm{Mg}$ & 0.79 & 0.81 & 0.81 \\
\hline
\end{tabular}

本文1990年3 月 21 日收到.

* 因家教委博士点基金资助项目. 
滑石、蛇蚊石等与其伴生; 在束状或纤维状集合体中,还偶而见到可分辨的平行消光的内石与！ 其交生在一起. 表 1 列出了两个镁质闪石颗粒的三个点的电子探针分析结果及其阳离子数. 电子探针分析委托中国地质科学院矿床研究所电子探针实验室用波谱法在 JEOL 733 仪器上 进行. 从表 1 中可以看出,龙泉肉石为贫钙、铝和镍的 $\mathrm{Mg}-\mathrm{Fe}$ 系列闪石.

\section{二、龙悬䦅质闪石的电子衍射研究}

作者以电子衍射为手段,对龙泉镁质闪石进行了空间群测定. 所有电子衍射照片在JEOL

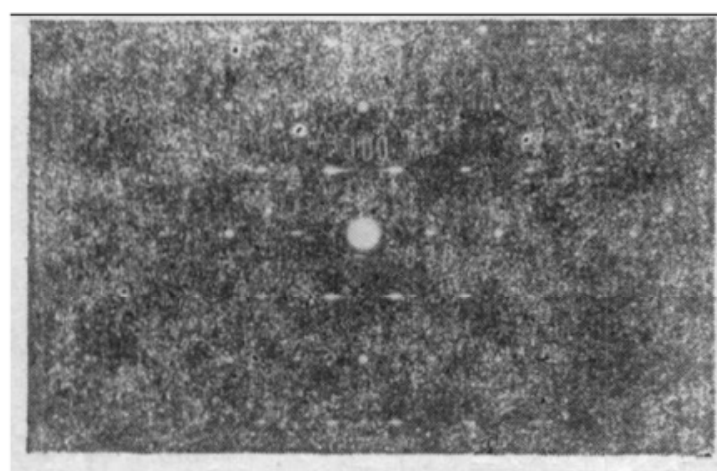

图 1 龙泉镁质内石的 [001] 电子行射照片

\section{$200 \mathrm{CX}$ 电镜下摄得.}

图 1 是本文研究的闪石的 $[001]$ 电子衍射图.

众所周知,对空间群为 $\mathrm{C} 2 / \mathrm{m}$ 的闪石而言, 所有 行射的指标应满足 $h+k-2 n$ 。 因而, $h 00$ 衍射 必须满足 $h-2 n ; 0 k 0$ 衍射必须满足 $k-2 n$. 然 而, 图 1 所示的 $h k 0$ 衍射花样按 $\mathrm{C} 2 / \mathrm{m}$ 格子指标时, 出现了 $h$ 为奇数的 $h 00$ 行射. 若再研究一下用更高 电压的透射电镜拍摄的 $h k 0$ 衍射花样发现, 其中除 有 $h$ 为奇数的 $h 00$ 行射外, 还出现了其它违背 $\mathrm{C} 2 / \mathrm{m}$ 空间群的衍射, 即 $h+k \neq 2 n$ 的衍射. 但这种衍射的强度极其微弱. 这些弱点是晶体结 构对称不是 $\mathrm{C} 2 / \mathrm{m}$ 引起的吗? 抑或是由其它因素引起的呢? 从龙泉镁质闪石的 [010]衍射照 片(图 2) 可以找到问题的答案.

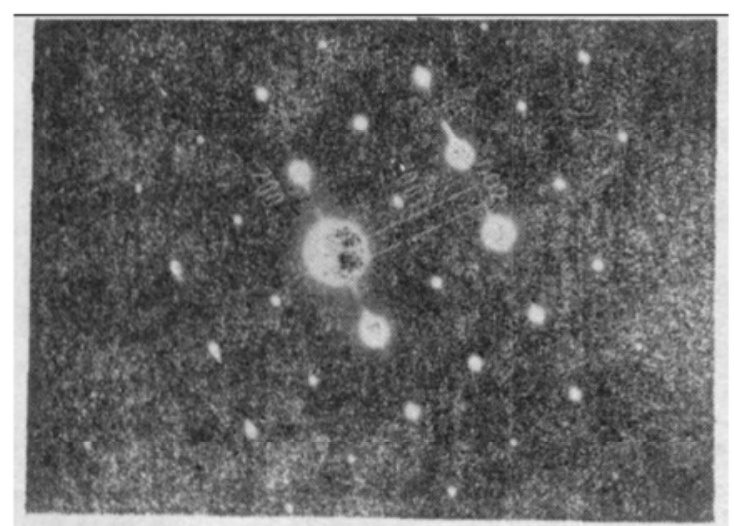

图 2 龙泉镜质似石的 $[010]$ 电子衍射盟片 图中用白线樞出了正交镂质贝石的倒易格子,未用线连接 的强点为单狳镜质认石的行射,其 001 及 200 行射已标明

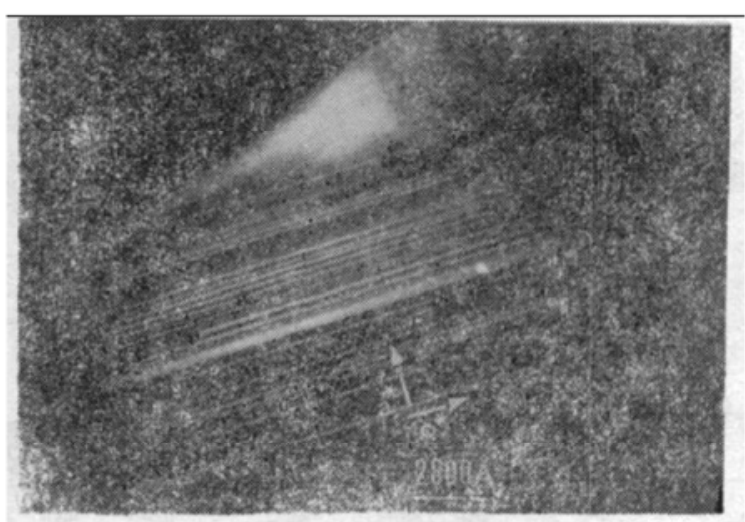

图 3 龙泉镁质闪石的暗场象 图中示出了直队石 $a^{*}$ 和 $b^{*}$ 方向

从图 2 不难看出, 这一衍射花样是由两种物相的衍射花样叠合而成. 其中强点是单斜镁 质闪石的 $h 0 l$ 衍射, 001 及 200 衍射已被标出. 从图 2 可知, 单斜镁质闪石的衍射存在条 件为 $h=2 n$. 这一衍射存在条件与空间群 $\mathrm{C} 2 / \mathrm{m}$ 所要求的条件一致. 据此, 作者将产生这些 行射的单斜闪石的空间群定为 $\mathrm{C} 2 / \mathrm{m}$. 衍射炤片的弱点, 具直角格子 (图 2 中白线相连的格 子, 其 002 用另一种字体标出)的特点. 显然, 它们是正交闪石的衍射产物, 其衍射存在条件为 $h 0 l$ : 无条件; $00 l: l-2 n ; h 00: h-2 n$. 这一条件与 Pnma 空间群的衍射存在条件吻合. 从 图 2 还可以得出上述两个不同晶系镁质闪石的倒易晶胞、晶胞参数和晶体取向的如下关系: 


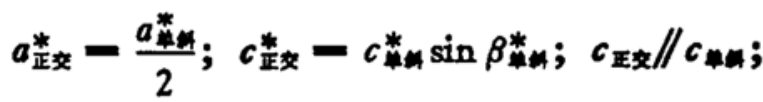

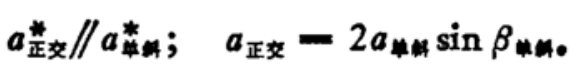

这些关系表明龙泉闪石是单斜和正交两种镁质闪石的平行交生体。透射电镜下的暗场象(图 3）直观地显示了这种交生关系. 交生密集处, 正交镁质闪石叶片的厚度仅几个晶胞的宽度 (指 $a$ 轴方向). 能谱分析表明呈交生关系的两相的成分没有差异. 据此, 作者认为上述平行 交生体是相变不彻底的产物.

由于平行交生体中 Pnma 相的 $h 00$ 衍射点列的点间距正好为 $\mathrm{C} 2 / \mathrm{m}$ 相这一相应间. 距 的一半, 因而对单斜闪石相的 [010] 衍射花样进行指标时, $h 00$ 行射出现了 $h$ 为奇数的指标. 这一情况也会出现在图 1 的 $h k 0$ 衍射中. 不难理解, 该衍射花样中出现的 $h$ 为奇数的 $h 00$ 衍 射, 实际上是正交闪石的衍射. 另外,用正交格子对图 1 中的包括弱点在内的全部衍射进行指 标, 则其衍射存在条件为

$$
h k 0: h=2 n ; h 00: h=2 n ; 0 k 0: k-2 n \text {. }
$$

此条件正好符合 Pnma 对称的衍射要求. 这进一步证明, [001] 衍射图中的强度很弱的违反 $\mathrm{C} 2 / \mathrm{m}$ 对称的衍射是由于正交闪石重叠所致. 综合以上分析可知,龙泉闪石的 [001]衍射花样 中的强点是单斜闪石的衍射, 也是正交闪石的衍射玟; 而弱点只是正交闪石的衍射. 两闪石的 空间群分别为 $\mathrm{C} 2 / \mathrm{m}$ 和 Pnma; 两者的交生面平行 (100) 面网.

自 Bown ${ }^{[1]}$ 发现与透闪石交生的 $\mathrm{Mg}-\mathrm{Fe}$ 单斜闪石的空间群为 $\mathrm{P} 2_{1} / \mathrm{m}$ 以来,不少研究者 相继证实了这一发现, 并已被矿物学家所公认 ${ }^{[2,3]}$. $\mathrm{P} 2_{1} / \mathrm{m}$ 闪石的晶体结构中, 应有两种对称等 效的 $\mathrm{Si}-\mathrm{O}$ 四面体双链. 作者对龙泉镁质闪石交生体中单斜闪石的空间群已确定为 $\mathrm{C} 2 / \mathrm{m}$, 由此表明其晶体结构中只有一种对称等效的 Si-O 四面体双链, 因此它应是镁闪石的高温 相. 作者将其简称为高镁闪石.

至于交生体中的正交闪石的结构态, 则认为它与直闪石相当. Chisholm ${ }^{[4]}$ 在讨论和推导 辉闪石 (pyribole) 结构型时指出, 高温态的正交闪石与直闪石一样,空间群都是 Pnma, 但由 于结构中只有一种四面体双链, 因而具有非空间群对称性 (non-space group symmetry). 它 的 $h k 0$ 衍射的衍射存在条件与 Pnma 空间群要求的一致外,还有 $h+2 k-4 n$ (原作者误为 $2 h+k-4 n$ ) 的附加条件. 龙泉镁质闪石交生体的 $h k 0$ 行射中, $h+2 k-4 n$ 的衍射（按 Pnma 格子指标) 为明锐的强斑, 而违反这一条件者为弱衍射, 除 200、400等衍射外, 均需在 $400 \mathrm{kV}$ 的透射电子显微镜下才能见到. 这些弱衍射的出现, 标志着交生体中的正交闪石不是 高温直闪石; 而是直闪石. 也就是说, 与 $\mathrm{C} 2 / \mathrm{m}$ 内石不同, 其晶体结构中有两种 $\mathrm{Si}-\mathrm{O}$ 四面体 双链. 此外, 交生体的 [001] 衍射图中, 未见出现直闪石应有的 $2 h+k-4 n$ 的衍射, 这与直 闪石晶畴细小 (宽度 $<100 \AA$ ) 有关. 图 3 中, 细窄的片晶就是一个证明. 晶畴细小, 往往是快 速冷却条件下发生相变的标志. 片晶的 $h k 0$ 衍射不具有非空间对称性则说明, 只有一种四面 体双链的高温直闪石结构是不稳定的, 而且不能淬火保存.

\section{三、结 论}

1. 龙泉镁质闪石由镁闪石 $-\mathrm{C} 2 / \mathrm{m}$ 和直闪石交生而成. 交生体的平均 $\mathrm{Mg} / \mathrm{Mg}+\mathrm{Fe}$ 比 值为 0.80 . 由于, 交生的两相在成分上没有差异, 可以认为该闪石在化学上与平均化学式为 $\left(\mathrm{Mg}_{5.46} \mathrm{Fe}_{1.34} \mathrm{Ca}_{0.10} \mathrm{Mn}_{0.06} \mathrm{Cr}_{0.01} \mathrm{Na}_{0.01} \mathrm{Al}_{0.03}\right)_{7.01} \mathrm{Si}_{7.99} \mathrm{O}_{22}(\mathrm{OH}, \mathrm{F})_{2}$ 的闪石相当. 
2. Prewitt 等跑认为锠内石- $2 / \mathrm{m}$ 不可淬火得到. 作者在龙泉镁质内石中发现了镁内 石一 $\mathrm{C} 2 / \mathrm{m}$. 这一结果与上述结论相悖. 龙泉镁内石 $-\mathrm{C} 2 / \mathrm{m}$ 的确认证明, 在一定地质条件 下, 锠内石 $-\mathrm{C} 2 / \mathrm{m}$ 可以被保存下来. 它是断裂带热动变质条件下高温快速冷却的特知产 物. 这一条件可由与之共生的花岗质玻化岩的存在所证实.

3. 高直内石是不能淬火保存的, 因而交生体中的正交肉石以直内石形式产出, 其晶烣宽度 在 $100 \AA$ 以下.

致谢: 南京大学地球科学系罗谷风教授曾对本文提出过有益的意见;博士生朱云鹤提供了样品, 对此作 者表示深切的谢意.

\section{考 文 樯}

[1] Bown, G. A., Amer. Mineral., 51(1966), 259-260.

[2] Hawthorne, F. C., Reviews in Mineralogy, 9A(1981), 59-63.

[3] Ghose, S., Reviews in Mineralogy, 9A(1981). 338-339.

[1] Chisholm, J. E., Mineral. Mag., 44(1981), 205-216.

I.5] Prewitt, C. T. and Papike, J. J., Earth Planet. Sci. Letters, 8(1970), 448-450. 